\title{
Thermodynamics of sodium dodecyl sulphate (SDS) micellization in the presence of some biologically relevant $\mathrm{pH}$ buffers
}

\author{
Joanna Makowska ${ }^{1}$ Dariusz Wyrzykowski ${ }^{1}$ Bogusław Pilarski ${ }^{2} \cdot$ \\ Lech Chmurzyński ${ }^{1}$
}

Received: 18 September 2014/Accepted: 13 March 2015/Published online: 26 March 2015

(C) The Author(s) 2015. This article is published with open access at Springerlink.com

\begin{abstract}
Three complementary experimental techniques: isothermal titration calorimetry, differential scanning calorimetry and conductometric titration, have successfully been applied to describe the process of sodium dodecyl sulphate (SDS) micellization in the presence of $\mathrm{pH}$ buffering substances, namely 2 -(N-morpholino)ethanesulfonic acid, piperazine-N,N'-bis(2-ethanesulfonic acid), 4-(2-hydroxyethyl)-1-piperazineethanesulfonic acid and 3-(N-morpholino)propanesulfonic acid, commonly used in biological experiments as well as in calorimetric studies. The measurements were taken in aqueous solutions (pH 6.5), at $298.15 \mathrm{~K}$. The influence of the buffer components as well as the composition of the system under study on the critical micelle concentration, the molar standard enthalpy for micelle formation $\left(\Delta_{\text {mic }} H^{0}\right)$ and the molar heat capacity that corresponds to the thermal midpoint $\left(T_{\mathrm{m}}\right)$ of micelle transition has been discussed. It has been shown that the dependence of SDS stability on the kind of buffer may be helpful for the precise interpretation of the molecular recognition processes.
\end{abstract}

Keywords Isothermal titration calorimetry .

DSC - Conductometric titration - Surfactants - CMC . Micellization

Joanna Makowska

joanna.makowska@ug.edu.pl

1 University of Gdańsk, Wita Stwosza 63, 80-308 Gdańsk, Poland

2 Cerko Sp. z o.o. Sp.K, Al. Zwycięstwa 96/98, 81-451 Gdynia, Poland

\section{Introduction}

Surfactants (surface active agents) (Fig. 1) are present in a large number of commercial products that are widely used in everyday life, for example, in detergents, cosmetics as well as in some types of antibiotics and herbicides. Furthermore, it has been well established that the presence of surfactants in the systems under study changes the physicochemical properties of the compounds with biological relevance $[1-3]$.

The title surfactant, sodium dodecyl sulphate (SDS), is a very simple model of a phospholipid membrane with a negative surface charge. It is widely used to mimic many aspects of natural interactions on membranes and to study an initial physicochemical characterization of systems under investigation. It has been found that the backbone conformations of some peptide hormones are influenced by the presence of the SDS micelles. For example, bradykinin, the 9-amino acid peptide (Arg-Pro-Pro-Gly-Phe-SerPro-Phe-Arg) that takes part in the pathogenesis of many diseases such as arthritis, pancreatitis or hypertension, is conformationally flexible in aqueous solutions; however, in the presence of SDS, it adopts a specific $\beta$-turnlike conformation $[4,5]$. Other biologically relevant molecules such as substance P (Arg-Pro-Lys-Pro-Gln-Gln-PhePhe-Gly-Leu-Met- $\mathrm{NH}_{2}$ ), a neuromodulator involved in the transmission of pain information, can form complexes with the SDS micelles, thus resulting in the change of the peptide conformation from a relatively unordered to a very specific one that enables to penetrate the micelles [6].

Conformational and physicochemical studies of biological molecules in SDS environment are usually carried out in buffer solutions. However, to the best of our knowledge, there are no reports on stabilities of SDS in biologically relevant $\mathrm{pH}$ buffers. Consequently, it was the reason that 
(a)

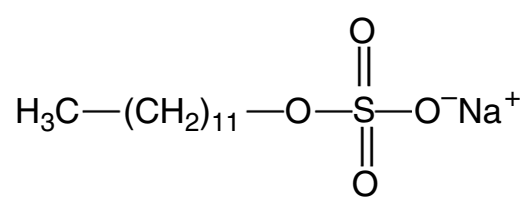

Represented as

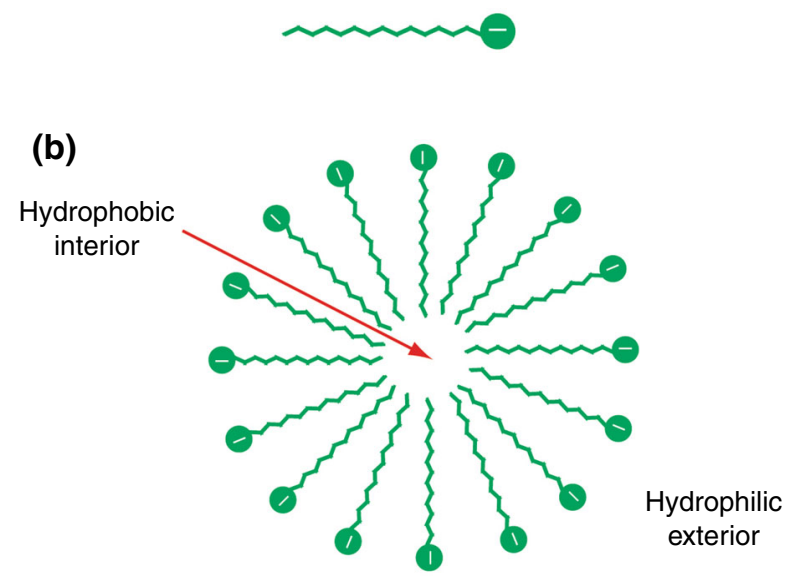

Fig. 1 Schematic diagram of the structure of the micelle (with the hydrophobic tails and hydrophilic heads) of the sodium dodecyl sulphate (SDS)

prompted us to embark on these studies. In this paper, we report the results of our studies on the thermodynamics of SDS micellization in the presence of some biologically relevant $\mathrm{pH}$ buffers (Fig. 2): 2-(N-morpholino)ethanesulfonic acid (MES), piperazine-N,N'-bis(2-ethanesulfonic acid) (PIPES), 4-(2-hydroxyethyl)-1-piperazineethanesulfonic acid (HEPES) and 3-(N-morpholino)propanesulfonic acid (MOPS), commonly used in biological experiments as well as in calorimetric studies [7-11]. The knowledge of stability of SDS in buffers may be helpful for the in-depth interpretation of the molecular recognition processes.

\section{Materials and methods}

\section{Differential scanning calorimetry (DSC)}

Calorimetric measurements were made with the VP-DSC microcalorimeter (MicroCal) at a scanning rate $90{ }^{\circ} \mathrm{C} / 1 \mathrm{~h}$. Scans were obtained at $50 \mathrm{mM}$ buffer solutions (MES, HEPES, MOPS and PIPES) containing $4 \mathrm{mM}$ SDS, at the $\mathrm{pH}$ of 6.5 and in the range of temperature from 25 to $80{ }^{\circ} \mathrm{C}$. The cell volume was $0.5 \mathrm{~mL}$. The reversibility of the transition was checked by cooling and reheating the same sample. These measurements were recorded three times. Results from DSC measurements were analysed with the Origin 7.0 software from MicroCal using the routines of the software provided with the instrument [12]. (a)<smiles>O=S(=O)(O)CCN1CCOCC1</smiles><smiles>O=S(=O)(O)CCN1CCN(CCS(=O)(=O)O)CC1</smiles>

(c)<smiles>O=S(=O)(O)CCN1CCN(CCO)CC1</smiles>

(d)<smiles>O=S(=O)(O)CCCN1CCOCC1</smiles>

Fig. 2 Structures of the biologically active buffers: a MES, b PIPES, c HEPES, d MOPS

\section{Isothermal titration calorimetry (ITC)}

All ITC experiments were performed at $298.15 \mathrm{~K}$ using the AutoITC isothermal titration calorimeter (MicroCal Inc. GE Healthcare, Northampton, USA) with a $1.4491-\mathrm{mL}$ sample and the reference cells. The reference cell contained distilled water. All details of the measuring devices and the experimental setup were described previously [13]. SDS was dissolved directly into $50 \mathrm{mM}$ buffer solution of MES, HEPES, MOPS and PIPES. The $\mathrm{pH}$ of the buffer solution was adjusted to 6.5 with $0.1 \mathrm{M} \mathrm{HClO}_{4}$. The experiment consisted of injecting $10.02 \mu \mathrm{L}$ ( 29 injections, $2 \mu \mathrm{L}$ for the first injection only) of ca. $20 \mathrm{mM}$ buffered solution of SDS into the reaction cell which contained ca. $1 \mathrm{mM}$ buffered solution of SDS. The titrant was injected at 4-min intervals to ensure that the titration peak returned to the baseline before the next injection. Each injection lasted $20 \mathrm{~s}$. For homogeneous mixing in the cell, the stirrer speed was kept constant at $300 \mathrm{rpm}$.

\section{Conductometric studies}

Conductometric measurements were accomplished on the Cerko Lab System microtitration unit fitted with a 5-mL Hamilton's syringe, a CD-201 conductometric cell with a constant $k=0.096 \mathrm{~cm}^{-1}$ (HYDROMET). The conductometric electrode was standardized with conductivity standards 
Fig. 3 Heat capacity curves of SDS in: MES (squares), MOPS (bullets), PIPES (triangles) and HEPES (upside down triangles) buffers, determined by DSC

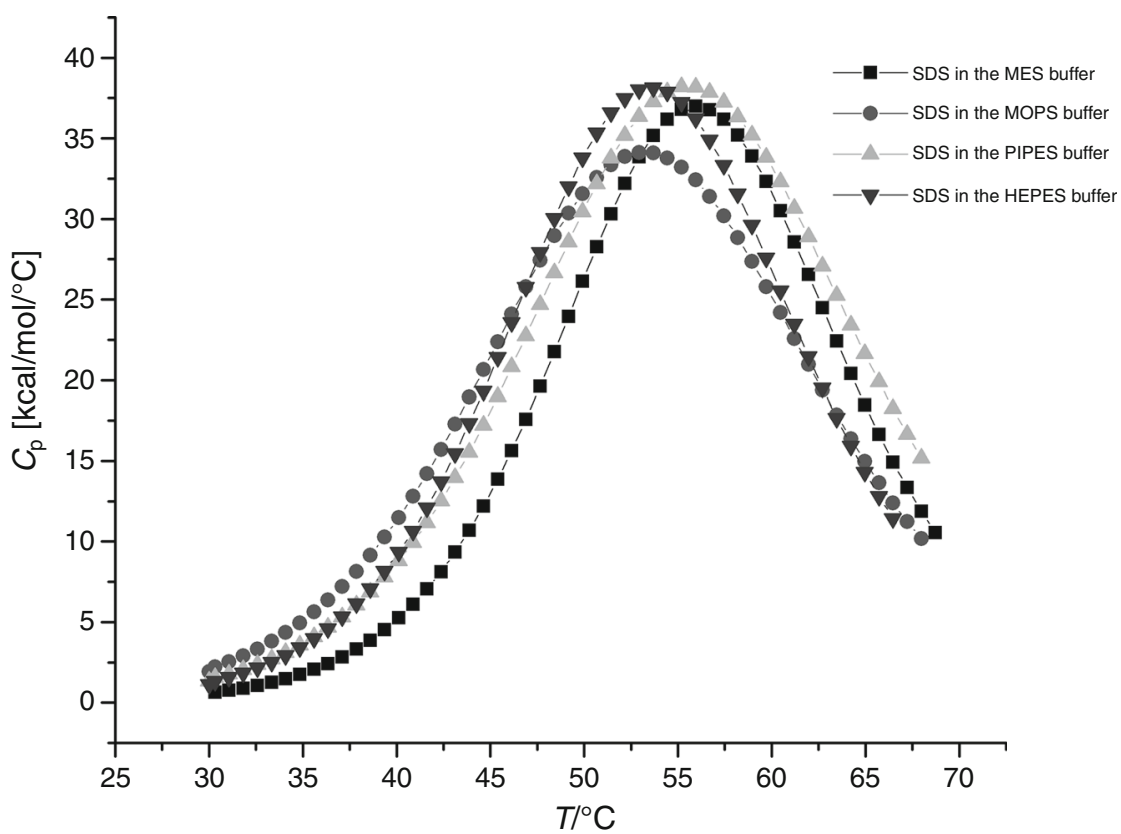

(aqueous $\mathrm{KCl}$ solutions) of conductivity 84 and $200 \mu \mathrm{S} / \mathrm{cm}$, purchased from Hamilton Company. The measurements were taken at $298.15 \pm 0.10 \mathrm{~K}$ controlled by the Lauda E100 circulation thermostat.

\section{Results and discussion}

The quantity measured by DSC is the difference between the heat capacity of buffer solution of SDS and that of the selected buffer. To perform a DSC measurement of SDS micellization, the reference cell was filled with MES, HEPES, MOPS and PIPES buffers, respectively, and the sample cell with the SDS buffered solutions. Then, the samples were heated at a constant scan rate $\left(90^{\circ} \mathrm{C} / 1 \mathrm{~h}\right)$. When a SDS demicellization occurs during DSC measurements, the absorption of heat results in temperature difference $(\Delta T)$ between the cells. In Fig. 3, the heat capacity curves of SDS in four different buffers are shown. It should be noted that SDS micelles behave similar in the HEPES and MOPS solutions. The transition temperature of SDS for both above-mentioned buffers is $\sim 54{ }^{\circ} \mathrm{C}$ (Table 1). In the MES and PIPES buffers, the transition temperature of SDS increases about $2{ }^{\circ} \mathrm{C}$. However, the DSC results show that the stabilities of the SDS micelles in the buffers studied are comparable. The most significant changes for all buffers under study occur in the range of the temperature $54-56{ }^{\circ} \mathrm{C}$ (Table 1). Thus, above this range of temperature, the monomeric SDS species dominate in the solution.

The ITC and the conductometric titration (CT) methods have been applied to determine critical micelle concentrations and enthalpies of micelle formation $\left(\Delta_{\text {mic }} H\right)$ of
Table 1 Transition temperature and the enthalpy of demicellization of SDS in $50 \mathrm{mM}$ buffer solutions of $\mathrm{pH}=6.5$, at $T=298.15 \mathrm{~K}$

\begin{tabular}{llll}
\hline $\begin{array}{l}4 \mathrm{mM} \mathrm{SDS} \\
\text { with buffer }\end{array}$ & $\begin{array}{l}\text { Temperature } \\
\text { range } /{ }^{\circ} \mathrm{C}\end{array}$ & $\begin{array}{l}\Delta H / \\
\mathrm{kcal} \mathrm{mol}\end{array}$ & $\begin{array}{l}\mathrm{T}_{\mathrm{m}} /{ }^{\circ} \mathrm{C} \text { (non-two- } \\
\text { state model) }\end{array}$ \\
\hline MES & $30.3-68.0$ & $0.982(0.030)$ & 55.85 \\
HEPES & $30.6-67.5$ & $0.794(0.025)$ & 54.87 \\
MOPS & $29.7-68.1$ & $0.810(0.028)$ & 53.80 \\
PIPES & $30.3-68.7$ & $0.895(0.039)$ & 56.66 \\
\hline
\end{tabular}

SDS. The representative titration curves for the SDS micellization in $50 \mathrm{mM}$ PIPES and MOPS buffer (pH 6.5) are shown in Fig. 4, whereas the CMC and $\Delta_{\text {mic }} H$ values of SDS in the systems under study are collected in Table 2. The presence of the buffer substances favours micelle formation. The CMC of SDS is significantly lower in comparison with that of the water-SDS system (CMC $8 \mathrm{mM}$ ) [14]. The lowest CMC value was found for the PIPES buffer. This finding can be attributed to the ionic strength that is the highest in this system. The high concentration of the sodium ions (the counter-ions) reduces the electrostatic repulsion between the negative ionic headgroups (Table 2), leading to the decrease in the CMC value. In the conditions under study, the stabilization of micelle effect is not overcompensated by sequestering the SDS molecules by the buffer's component that hinders the formation of the micelles.

In the presence of buffer component, the self-assembly of SDS becomes less exothermic than in the buffer-free aqueous solutions (Table 2) [15]. This finding can be attributed to the release of buffer component from the layers around the hydrophobic parts of the SDS molecule. It is 
(a)

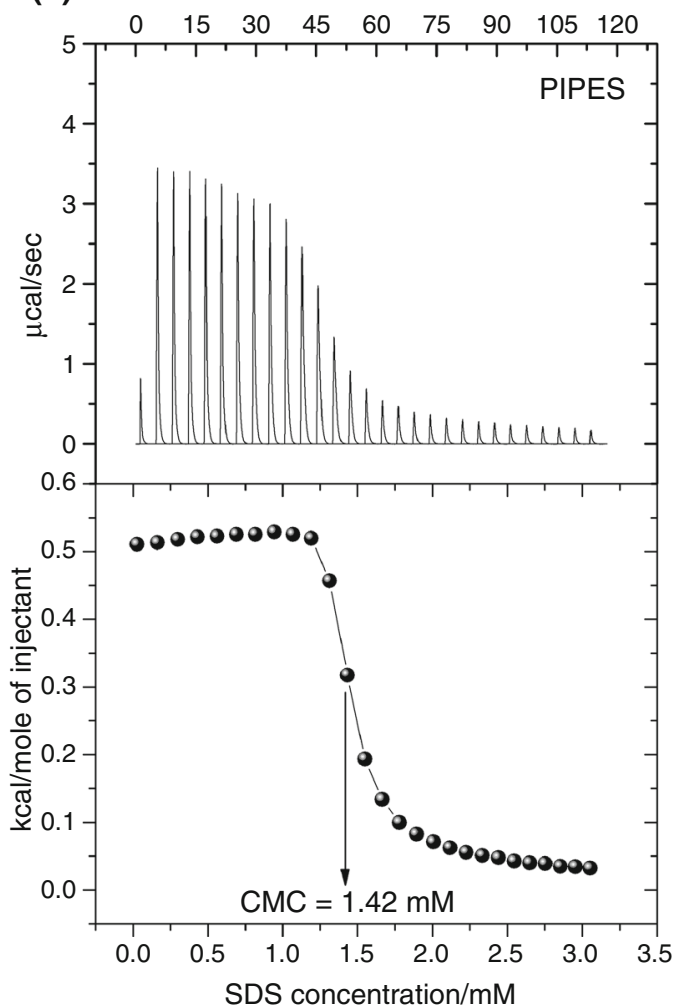

(b)

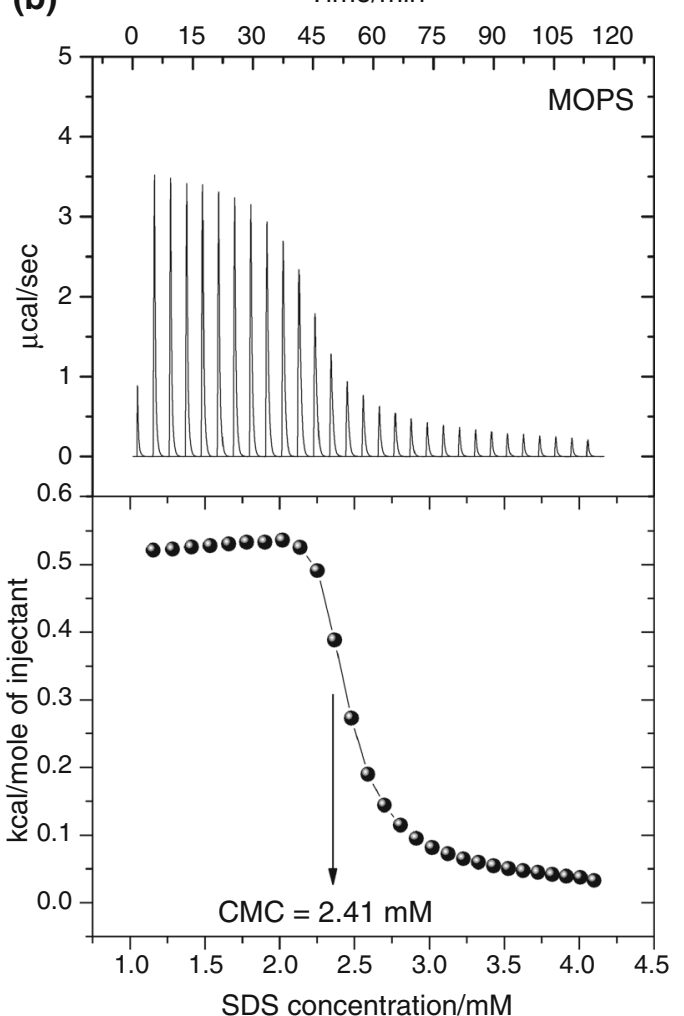

Fig. 4 Formation of SDS micelles in $50 \mathrm{mM}$ PIPES and MOPS of a pH of 6, at 298.15 K

Table 2 Critical micelle concentration (CMC) and the enthalpy of micellization $\left(\Delta_{\text {mic }} H\right)$ of SDS in $50 \mathrm{mM}$ buffer solutions of a pH of 6.5 , at $298.15 \mathrm{~K}$

\begin{tabular}{|c|c|c|c|c|c|}
\hline \multirow[t]{2}{*}{ Buffer } & \multirow[t]{2}{*}{$\mathrm{p} K_{\mathrm{a}}$} & \multirow{2}{*}{$\begin{array}{l}\text { Species distribution } \\
\text { of buffer components at } \mathrm{pH} 6.5\end{array}$} & \multicolumn{2}{|c|}{$\mathrm{CMC} / \mathrm{mM}$} & \multirow{2}{*}{$\begin{array}{l}\Delta_{\text {mic }} H / \mathrm{kcal} \\
\mathrm{mo}^{-1}\end{array}$} \\
\hline & & & ITC & $\mathrm{CT}$ & \\
\hline PIPES & 7.14 & $\mathrm{HL}^{-}=\mathrm{L}^{2-}+\mathrm{H}^{+}(81 \% \mathrm{HL}: 19 \% \mathrm{~L})$ & 1.42 & 1.9 & -0.473 \\
\hline HEPES & 7.56 & $\mathrm{HL}=\mathrm{L}^{-}+\mathrm{H}^{+}(92 \% \mathrm{HL}: 8 \% \mathrm{~L})$ & 2.41 & 2.45 & -0.368 \\
\hline MOPS & 7.18 & $\mathrm{HL}=\mathrm{L}^{-}+\mathrm{H}^{+}(83 \% \mathrm{HL}: 17 \% \mathrm{~L})$ & 2.43 & 2.35 & -0.464 \\
\hline MES & 6.27 & $\mathrm{HL}=\mathrm{L}^{-}+\mathrm{H}^{+}(37 \% \mathrm{HL}: 63 \% \mathrm{~L})$ & 2.45 & 2.48 & -0.384 \\
\hline
\end{tabular}

also worth noticing that there is no correlation between the enthalpy of buffer ionization [16] and the enthalpy of micellization.

\section{Conclusions}

The calorimetric studies (DSC and ITC) supported by conductometric measurements have successfully been applied to characterize the stability of the SDS micelles in the presence of some biologically relevant $\mathrm{pH}$ buffers. DSC measurements revealed that in the system under study (pH 6.5, $50 \mathrm{mM}$ buffer solution), the SDS micelles are stable up to ca. $55^{\circ} \mathrm{C}$. The highest thermal stability of the micelles was found at the PIPES system. Based on ITC as well as CT data, it has been found that both the CMC value and the enthalpy of micelle formation $\left(\Delta_{\text {mic }} H\right)$ are governed by the presence of the buffer component. The highest ionic strength of the solution the lowest CMC was observed. The interaction of buffer component with the monomeric SDS species results in lowering the exothermic effect of micellization in comparison with the free salt system. This phenomenon can be assigned to the endothermic effect connected with the buffer-surfactant dissociation process.

The study reveals that carrying out the measurements in the buffer solution that involves the micelle formation, the experimental conditions such as the range of temperatures as well as the type of buffer substance must be taken into consideration during designing the experiments. 
Acknowledgements DSC measurements were supported by a Grant from the Polish National Science Centre (NCN 2011/01/D/ST4/ 04497).

Open Access This article is distributed under the terms of the Creative Commons Attribution License which permits any use, distribution, and reproduction in any medium, provided the original author(s) and the source are credited.

\section{References}

1. Bal W, Kozłowski H, Lisowski M, Pettit L, Robbins R, Safavi A. A dramatic change in the interaction of $\mathrm{Cu}$ (II) with bio-peptides promoted by SDS-a model for complex formation on a membrane surface. J Inorg Biochem. 1994;55:41-52.

2. Otzen DE. Protein unfolding in detergents: effect of micelle structure, ionic strength, $\mathrm{pH}$, and temperature. Biophys J. 2002; 83:2219-30.

3. Otzen DE. Protein-surfactant interactions: a tale of many states. Biochim Biophys Acta. 2011;1814:562-91.

4. Cann JR, Vavrek RJ, Stewart JM, Mueller DD. Conformational aspects of the interaction of bradykinin and related peptide with sodium dodecyl sulfate. J Am Chem Soc. 1990;112:1357-64.

5. Lee SC, Russell AF, Ladig WD. Three-dimensional structure of bradykinin in SDS micelles. Study using nuclear magnetic resonance, distance geometry, and restrained molecular mechanics and dynamics. Int J Pept Protein Res. 1990;35:367-77.

6. Woolley GA, Deber CM. Peptides in membranes: lipid-induced secondary structure of substance P. Biopolymers. 1987;26:109-21.

7. Good NE, Winget GD, Winter W, Connoly TN, Izawa S, Singh RMM. Hydrogen ion buffers for biological research. Biochemistry. 1966;5:467-77.
8. Christensen T, Gooden DM, Kung JE, Toone EJ. Additivity and the physical basis of multivalency effects: a thermo-dynamic investigation of the calcium EDTA interaction. J Am Chem Soc. 2003;125:7357-66.

9. Wyrzykowski D, Chmurzyński L. Thermodynamics of citrate complexation with $\mathrm{Mn}^{2+}, \mathrm{Co}^{2+}, \mathrm{Ni}^{2+}$ and $\mathrm{Zn}^{2+}$ ions. J Therm Anal Calorim. 2010;102:61-4.

10. Wyrzykowski D, Zarzeczańska D, Jacewicz D, Chmurzyński L. Investigation of copper(II) complexation by glycylglycine using isothermal titration calorimetry. J Therm Anal Calorim. 2011; 105:1043-7.

11. Wyrzykowski D, Czupryniak J, Ossowski T, Chmurzyński L. Thermodynamic interactions of the alkaline earth metal ions with citric acid. J Therm Anal Calorim. 2010;102:149-54.

12. Plotnikov V, Rochalski A, Brandts M, Brandts JF, Williston S, Frasca V, Lin LN. An autosampling differential scanning calorimeter instrument for studying molecular interactions. Assay Drug Dev Technol. 2002;1:83-90.

13. Wyrzykowski D, Pilarski B, Jacewicz D, Chmurzyński L. Investigation of metal-buffer interactions using isothermal titration calorimetry. J Therm Anal Calorim. 2013;111:1829-36.

14. Benito I, Garcia MA, Monge C, Saz JM, Marina ML. Spectrophotometric and conductometric determination of the critical micellar concentration of sodium dodecyl sulfate and cetyltrimethylammonium bromide micellar systems modified by alcohols and salts. Colloids Surf A. 1997;125:221-4.

15. Marcolongo JP, Mirenda M. Thermodynamics of sodium dodecyl sulfate (SDS) micellization: an undergraduate laboratory experiment. J Chem Edu. 2011;88:629-33.

16. Goldberg RN, Kishore N, Lennen RM. Thermodynamic quantities for the ionization reactions of buffers. J Phys Chem Ref Data. 2002;31:231-70. 